\title{
In vitro Antifungal Activity of a Novel
}

\section{Antimicrobial Peptide AMP-I7 Against Planktonic Cells and Biofilms of Cryptococcus neoformans}

\author{
Longbing Yang', Zhuqing Tian', Luoxiong Zhou',2, Lijuan Zhu', Chaoqin Sun', Mingjiao Huang', \\ Jian Peng ${ }^{1,3}$, Guo Guo $1,3,4$
}

'School of Basic Medical Sciences, The Key and Characteristic Laboratory of Modern Pathogen Biology, Guizhou Medical University, Guiyang, 550025, People's Republic of China; ${ }^{2}$ School of Public Health, Guizhou Medical University, Guiyang, 550025, People's Republic of China; ${ }^{3}$ Key Laboratory of Environmental Pollution Monitoring and Disease Control, Ministry of Education, Guizhou Medical University, Guiyang, 550025, People's Republic of China; ${ }^{4}$ Translational Medicine Research Center, Guizhou Medical University, Guiyang, 550025, People's Republic of China

Correspondence: Guo Guo, Building Wuben, School of Basic Medical Sciences, Guizhou Medical University, College Town, Gui'an New District, Guiyang, 550025, People’s Republic of China, Tel/fax +86 85 I 882 59268, Email guoguojsc@I63.com

Background: Cryptococcus neoformans is a common human fungal pathogen in immunocompromised people, as well as a prevalent cause of meningitis in HIV-infected individuals. With the emergence of clinical fungal resistance and the shortage of antifungal drugs, it is urgent to discover novel antifungal agents. AMP-17, a novel antimicrobial peptide from Musca domestica, has antifungal activity against $C$. neoformans. However, its antifungal and anti-biofilm activities remain unclear. Thus, this study aimed to evaluate the antifungal activity of AMP-17 against planktonic cells and biofilms of $C$. neoformans.

Methods: The minimum inhibitory concentration (MIC), the biofilm inhibitory and eradicating concentration (BIC and BEC) were determined by the broth microdilution assay or the 2, 3-bis-(2-methoxy-4-nitro-5-sulfophenyl)-2H-tetrazolium-5-carboxanilide (XTT) reduction assay, respectively. The inhibitory and killing activities of AMP-17 against $C$. neoformans were investigated through the time-inhibition/killing kinetic curves. The potential antifungal mechanism of AMP-17 was detected by flow cytometry, scanning electron microscopy (SEM) and confocal laser scanning microscopy (CLSM). The efficiency of AMP-17 against biofilm formation or preformed biofilm was evaluated by crystal violet staining and XTT reduction assays. The morphology of pre-biofilms was tested by optical microscopy (OM) and CLSM.

Results: AMP-17 exhibited in vitro antifungal activity against $C$. neoformans planktonic cells and biofilms, with MICs of $4 \sim 16 \mu \mathrm{g} / \mathrm{ml}$, $\mathrm{BIC}_{80}$ and $\mathrm{BEC}_{80}$ of $16 \sim 32 \mu \mathrm{g} / \mathrm{ml}, 64 \sim 128 \mu \mathrm{g} / \mathrm{ml}$, respectively. In addition, the $2 \times$ and $4 \times$ MIC of AMP-17 exhibited similar inhibition levels compared to the $2 \times$ and $4 \times$ MIC of the clinical drugs FLC and AMB in C. neoformans growth. Moreover, the time-kill results showed that AMP-17 ( $8 \times$ MIC) did not significantly eliminate colony forming units (CFU) after $6 \mathrm{~h}$ of treatment; however, there was 2.9- $\log$ reduction in CFU of $C$. neoformans. Furthermore, increasing of the permeability of the fungal cell membrane was observed with the treatment of AMP-17, since the vast change as fungal leakage and cell membrane disruption. However, the DNA binding assay of AMP-17 indicated that the peptide did not target DNA. Besides, AMP-17 was superior in inhibiting and eradicating biofilms of C. neoformans compared with FLC.

Conclusion: AMP-17 exhibited potential in vitro antifungal activity against the planktonic cells and biofilms of C. neoformans, and it may disrupt fungal cell membranes through multi-target interactions, which provides a promising therapeutic strategy and experimental basis for Cryptococcus-associated infections.

Keywords: antimicrobial peptides, AMP-17, Cryptococcus neoformans, antifungal mechanism, anti-biofilm

\section{Introduction}

Cryptococcus neoformans, an encapsulated pathogenic yeast-like fungus, causes cryptococcosis in immunocompetent and immunocompromised patients. ${ }^{1,2}$ In recent years, with the spread and epidemic of acquired immunodeficiency syndrome (AIDS), intensive chemotherapy of cancer patients and widespread use of immunosuppressive therapy and 
broad-spectrum antimicrobial agents, opportunistic pathogenic infections caused by $C$. neoformans have been increasing year after year. ${ }^{3,4}$ Furthermore, cryptococcal meningitis is the most common cause of meningitis in individuals with HIV in regions of the world with high rates of HIV infection. ${ }^{5,6}$ It remains the second most prevalent cause of death in patients with AIDS. ${ }^{6,7}$ The global burden of cryptococcosis is estimated to be 223,000 cases per year, with nearly 181,000 people dying each year. ${ }^{6,7}$ Hence, cryptococcosis, like other invasive fungal infections, is a challenging problem that necessitates focused research and the development of novel antifungal agents.

It has been reported that current recommendations induction therapy should consist of a combination of amphotericin B and 5-flucytosine, followed by a consolidation period of relatively high-dose fluconazole and a longer maintenance period of lowerdose fluconazole ${ }^{89}$ Although the best therapy for cryptococcosis is a combination of AMB and 5-FU, it is not generally utilized in resource-poor nations due to side effects and high costs. ${ }^{10}$ Therefore, fluconazole is still the most commonly used antifungal drug in clinical practice for the treatment and prevention of $C$. neoformans infection, and FLC has been the recommended classic treatment for recent years. ${ }^{5,11}$ However, the widespread use of FLC has caused the rapid emergence of resistant strains. ${ }^{12}$ More seriously, C. neoformans can easily form biofilms on solid surfaces like implants and medical devices, as well as sessile biofilms can serve as a storage facility for antimicrobial drugs resistant, resulting in long-term systemic infections. ${ }^{13,14}$ Biofilms are microbial communities attached to an external polymer matrix on a solid surface. ${ }^{15}$ C. neoformans biofilms consist of a complex network of yeast cells fused with a large amount of polysaccharide matrix. ${ }^{16}$ In particular, the glucuronoxylomannan (GXM) in the capsule of $C$. neoformans plays a central role in biofilm formation and pathogenesis. ${ }^{17}$ Biofilm formation allows microorganisms to survive in harsh environments, colonize and sow new niches, and confer protection against predation. ${ }^{18,19}$ The selfproduced polysaccharide-rich extracellular polymeric matrix (EPM) of biofilm renders sessile cryptococcal cells resistant to antimicrobial therapy, leading to fungal resistance. Furthermore, biofilm formation has been linked to persistent infections, as biofilms increase resistance to host immune mechanisms and antimicrobial therapies. ${ }^{20}$ Therefore, it is urgent to investigate novel, effective, and safe anti-biofilm drugs, which might be a promising strategy to prevent or treat $C$. neoformans infections.

Antimicrobial peptides (AMPs), which are a key component of most organisms' innate immune systems, have been testified to be effective antimicrobial infection agents. ${ }^{21}$ AMPs have been shown to have antiviral, antitumor, and immunomodulatory properties in addition to antimicrobial activity. ${ }^{22,23}$ Therefore, AMPs are being considered as a possible drug candidate in the near future. Antimicrobial peptide-17 (AMP-17), which was screened from the C. albicans-induced M. domestica transcriptome database, was identified as a potential antifungal agent in previous studies. ${ }^{24,25}$ Full-length ORF of the AMP-17 was $495 \mathrm{bp}$, encoding 164 amino acids, and had an isoelectric point (PI) of $6.09 .{ }^{25}$ In addition, it was discovered that AMP-17's secondary structure is primarily composed of three types: $\alpha$-helix, random coil, and extended strand. ${ }^{25}$ The $\alpha$-helical structure mainly forms a potential-dependent channel on the cell membrane, which changes the permeability of the cell membrane and causes the cell contents to leak, and has antimicrobial activity against gram-positive, negative bacteria, and fungi. Previous studies showed that AMP-17 has $\alpha$-helical structure relating with antimicrobial peptides. Furthermore, one research reported that AMP-17 exhibits heat resistance, freeze-thaw resistance, and is non-toxic to human red blood cells. ${ }^{26}$ Meanwhile, AMP-17 exhibits potential antifungal activity against a variety of clinical fungi and has been shown to destroy the integrity of the C. albicans cell wall, causing the cell membrane structure to be destroyed and the cell membrane permeability to increase. ${ }^{25-27}$ However, the antifungal and anti-biofilm activities of AMP-17 against C. neoformans in vitro remain unclear. Thus, more reliable and accurate data are needed to explain the antifungal and anti-biofilm effects of AMP-17 against C. neoformans.

Given the above, this study evaluated the in vitro antifungal activity of AMP-17 against $C$. neoformans planktonic cells and observed the damaging effect of AMP-17 on the planktonic cell membrane by flow cytometry, CLSM, and SEM images. Furthermore, we also investigated the effect of AMP -17 on the formation and maturation of $C$. neoformans biofilm and performed CLSM and OM image observations during the mature stage of C. neoformans biofilm to visualize possible biofilm destruction activities. 


\section{Materials and Methods}

\section{Antimicrobial Peptide}

AMP-17 was overproduced from pET-28a in Escherichia coli BL21 (DE3) and purified with Ni-NTA beads, as previously reported (Novagen, Germany). ${ }^{25,27}$ In addition, AMP-17 obtained a Chinese patent license in 2019. (Patent number: ZL 2016 10428119. 8).

\section{Microbial Strains}

A total of 18 C. neoformans (2 standard strains: H99 and KN99, 9 clinical strains: IFM56716, IFM56769, IFM56771, IFM56772, IFM56787, IFM56793, IFM56794, IFM56800, IFM56803 and 7 environmental strains: IFM56722, IFM56726, IFM56728, IFM56731, IFM56734, IFM56735, IFM56743) were used in this study. These strains originated from the Institute of Fungi, Chiba University School of Medicine, Japan. And these strains were kindly donated by Professor Yingqian Kang, the Department of Microbiology, Guizhou Medical University, Guiyang, China.

\section{Antifungal Susceptibility Testing}

The MIC of AMP-17 against C. neoformans planktonic cells was determined by referring to the microscale broth dilution method recommended by the M27-A3 documents of the Clinical and Laboratory Standard Institute (CLSI). ${ }^{28}$ Briefly, planktonic cells cultured in Sabouraud dextrose Broth (SDB; Solarbio, Beijing, China) were collected at mid-logarithmic phase, washed with $10 \mathrm{mM}$ phosphate-buffered saline (PBS, pH 7.4), and re-suspended at a density of $0.5 \sim 2.5 \times 10^{3}$ $\mathrm{CFU} / \mathrm{mL}$ in RPMI 1640 medium (Gibco, BRL Invitrogen, US). $100 \mu \mathrm{L}$ of fungal suspension and $100 \mu \mathrm{L}$ final concentration of $0.5 \sim 64 \mu \mathrm{g} / \mathrm{mL}$ AMP-17, $0.5 \sim 64 \mu \mathrm{g} / \mathrm{mL}$ FLC (Sigma, US) or $0.125 \sim 16 \mu \mathrm{g} / \mathrm{mL}$ AMB (Sigma, US) were added to a 96-well plate for susceptibility tests and incubated at $35^{\circ} \mathrm{C}$ for $72 \mathrm{~h}$. The $\mathrm{OD}_{630} \mathrm{~nm}$ value of each well was measured by a microplate reader. The lowest drug concentration corresponding to the growth inhibition $\geq 80 \%$ well was the MIC value of AMP-17 and FLC, whereas the MIC value of AMB corresponded to no visible fungal growth, compared to the negative control. The assays were conducted in triplicate, with each experiment replicated twice.

\section{Time-Inhibition/Killing Kinetics}

Time-inhibition/killing kinetics monitoring was carried out according to the previous study. ${ }^{29}$ Briefly, the fungal suspensions were adjusted to reach $\sim 10^{5} \mathrm{CFU} / \mathrm{mL}$ in sterile RPMI 1640 medium, and then $100 \mu \mathrm{L}$ of the fungal suspensions were transferred to 24-well plates containing $900 \mu \mathrm{L}$ of a specific concentration of AMP-17 (1 8× MIC), and the plate was incubated at $35{ }^{\circ} \mathrm{C}$ with shaking $(120 \mathrm{rpm})$. Then, the optical density $\left(\mathrm{OD}_{630} \mathrm{~nm}\right)$ of the culture was measured at a specific time. For the killing kinetics, $50 \mu \mathrm{L}$ samples with different concentration were diluted serially and inoculated on SDA plates at specific times. Colony forming units (CFU) were counted after the culture had been at $35^{\circ} \mathrm{C}$ for $48 \mathrm{~h}$. FLC and AMB were used as positive controls. The assays were conducted in triplicate, with each experiment replicated twice.

\section{Nucleotide Leakage}

Nucleotide release assay was performed according to the method proposed by Lemos et $\mathrm{al}^{30}$ with minor modifications. Briefly, the fungal suspensions were adjusted to reach $1.0 \times 10^{6} \mathrm{CFU} / \mathrm{mL}$ in $10 \mathrm{mM}$ PBS and incubated with AMP-17 (1 4× MIC). Cultures incubated with $10 \mathrm{mM}$ PBS served as growth controls. Following incubation, cell suspensions at different time points $(0,1,2,4,6,8 \mathrm{~h})$ were centrifuged at $10,000 \times \mathrm{g}$ for $10 \mathrm{~min}$, and the supernatants were evaluated for $\mathrm{OD}$ at $260 \mathrm{~nm}$ in a spectrophotometer (Biotech, USA). The assays were conducted in triplicate, with each experiment replicated twice.

\section{Flow Cytometry Analysis}

The effect of AMP-17 on membrane permeability was detected by flow cytometry, according to a previously described method, with minor modifications. ${ }^{31}$ Briefly, C. neoformans cells were diluted to $1.0 \times 10^{6} \mathrm{CFU} / \mathrm{mL}$. Cell suspensions were incubated for $6 \mathrm{~h}$ at $35^{\circ} \mathrm{C}$ with 1,2, and $4 \times$ MIC AMP-17. Subsequently, treated cells were incubated with $10 \mu \mathrm{M}$ 
propidium iodide (PI; Sigma, US) for 15 min, followed by washing and resuspension in sterile PBS. The percentage of PI-positive cells was determined using the FACScan instrument (Beckman, USA). Results were obtained from two independent experiments.

\section{Membrane Morphological Observation}

\section{Scanning Electron Microscopy (SEM)}

The effect of AMP-17 on the morphology of planktonic cells of $C$. neoformans was analyzed by Scanning electron microscopy. Briefly, C. neoformans cells $\left(1.0 \times 10^{6} \mathrm{CFU} / \mathrm{mL}\right)$ were seeded into 6-well plates and treated for $6 \mathrm{~h}$ at $35^{\circ} \mathrm{C}$ with 1, 2, and 4× MIC AMP-17 before being collected by centrifugation (5000 rpm for $5 \mathrm{~min}$ ). Subsequently, the samples of each group were washed thrice with $10 \mathrm{mM}$ PBS and fixed with $1 \mathrm{~mL} 2.5 \%$ of glutaraldehyde at $4{ }^{\circ} \mathrm{C}$ overnight. Then, the fixed samples were washed thrice in PBS and dehydrated in a graded sequence of ethanol $(50 \%, 70 \%, 90 \%$, and 100\%). Finally, the samples were observed under a Hitachi H-7650 SEM (Tokyo, Japan).

\section{Confocal Laser Scanning Microscopy (CLSM)}

C. neoformans cells $\left(1.0 \times 10^{6} \mathrm{CFU} / \mathrm{mL}\right)$ were seeded into 6-well plates and treated with 1, 2, and 4× MIC AMP-17 for 6 $\mathrm{h}$ at $35^{\circ} \mathrm{C}$, and then stained with PI at a final concentration of $10 \mu \mathrm{M}$ in the dark and incubated for $15 \mathrm{~min}$. The stained cells were washed three times in $10 \mathrm{mM}$ PBS before being resuspended in PBS. The samples were analyzed using CLSM (Olympus FV1000, Japan).

\section{DNA Binding Assay}

The DNA gel mobility shift assay was performed as described by Li et al ${ }^{32}$ with minor modifications. Briefly, Genomic DNA (50 ng) was mixed with 1, 2, 4× MIC AMP-17 in $10 \mu \mathrm{L}$, and the mixtures were incubated at $37{ }^{\circ} \mathrm{C}$ for $1 \mathrm{~h}$. The products were detected by $1 \%$ agarose gel electrophoresis, and DNA migration was observed on the 4600SF type gel imaging analysis system (Tanon, China). The experiment was repeated at least three times.

\section{Biofilm Formation}

Biofilm was prepared according to the method proposed by Pierce et al. ${ }^{33}$ Briefly, 3-5 single colonies were inoculated into $5 \mathrm{~mL}$ SDB medium and grown to the logarithmic growth phase at $35^{\circ} \mathrm{C}$. After washing three times with $10 \mathrm{mM}$ PBS and centrifugation at $3000 \times \mathrm{g}$ for $5 \mathrm{~min}$, the concentration of the fungal suspension was adjusted to $2 \times 10^{7}$ cells $/ \mathrm{mL}$ using DMEM medium (containing 10\% fetal bovine serum (FBS, Gibco)). The cell suspension (100 $\mu \mathrm{L}$ ) was then transferred to pre-treated wells of polystyrene 96-well plates with FBS and cultured at $35{ }^{\circ} \mathrm{C}$ for $48 \mathrm{~h}$ with shaking to generate a biofilm. Subsequently, the plankton cells were discarded after being washed three times in PBS. True biofilm was defined as fungal cells that remained attached to the polystyrene surface. All assays were carried out in triplicates.

The biofilm biomass was determined using crystal violet (CV; Solarbio, Beijing, China). The biofilms were fixed in absolute ethanol for 5 10 minutes before being allowed to dry. After that, each well was stained for 10 min with $0.5 \%$ $\mathrm{CV}$, and the excess dye was removed with PBS. The bound CV was dissolved in $30 \%$ acetic acid, and the absorbance was measured at $\mathrm{OD}_{560} \mathrm{~nm}$ on a microtiter plate reader (Biotek Epoch 2, USA).

\section{Effect of AMP-I7 in Preventing C. neoformans Biofilm Formation}

The effects of AMP-17 on C. neoformans biofilm formation were evaluated as described by Brilhante et al ${ }^{34}$ and Martinez et al, ${ }^{35}$ with some modifications. Briefly, the fungal suspensions were adjusted to $2.0 \times 10^{7}$ cells $/ \mathrm{mL}$ in DMEM medium (Gibco, BRL Invitrogen, US), then $100 \mu \mathrm{L}$ of the fungal suspensions were added to 96 -well polystyrene plates containing $100 \mu \mathrm{L}$ of AMP-17 at varied concentrations $(8 \sim 64 \mu \mathrm{g} / \mathrm{mL})$ and incubated for $48 \mathrm{~h}$ at $35^{\circ} \mathrm{C}$. Subsequently, the plate was washed thrice with sterile PBS, and the biofilm was quantified by the 2, 3-Bis-(2-Methoxy-4-Nitro5-Sulfophenyl)-2H-Tetrazolium-5-Carboxanilide (XTT; BBI, Shanghai, China) reduction assay and biofilm inhibitory concentration. The metabolic activity that inhibited $80 \%$ biofilm formation was the lowest biofilm inhibitory concentration $\left(\mathrm{BIC}_{80}\right)$ of AMP-17 compared to the negative control. The experiment was performed in triplicate and repeated twice. 


\section{Effect of AMP-I7 on Preformed Biofilm of C. neoformans}

The effects of AMP-17 against pre-biofilms of $C$. neoformans were analyzed as described by Kumari et al ${ }^{16}$ with some modifications. For the pre-biofilm assay, the biofilm was made as described in the previous section. Thereafter, serially double-diluted AMP-17 $(32 \sim 256 \mu \mathrm{g} / \mathrm{mL})$ was added into the wells of pre-washed and pre-biofilms, and the plate was incubated at $35{ }^{\circ} \mathrm{C}$ for $48 \mathrm{~h}$. Subsequently, the pre-biofilm was quantified by the XTT reduction assay and biofilmeradicating concentration. The metabolic activity that eradicated $80 \%$ of the pre-biofilm was the lowest biofilm eradication concentration $\left(\mathrm{BEC}_{80}\right)$ of AMP-17, compared to the negative control. The experiment was carried out in triplicate and repeated twice.

\section{Optical Microscopy Analysis}

The effect of AMP-17 against the structure of pre-biofilms was observed by inverting OM, as previously described, ${ }^{36}$ with slight modifications. Briefly, AMP-17 was added to a pre-biofilm 24-well plate containing sterile polylysine-treated coverslips for $6 \mathrm{~h}$, after which the supernatant was aspirated and washed with sterile PBS to remove the unattached cells. The samples were then stained with $0.5 \%(\mathrm{w} / \mathrm{v}) \mathrm{CV}$ for $10 \mathrm{~min}$ and washed three times with sterile PBS before being observed with an inverted OM (Nikon, Japan).

\section{Confocal Laser Scanning Microscope Analysis}

To evaluate the eradication effect of AMP-17 on pre-biofilms by CLSM, as previously described, ${ }^{37,38}$ with minor modifications. Briefly, A sterile polylysine-treated cover glass was used as the carrier, and the biofilm was grown for $48 \mathrm{~h}$ and treated with AMP-17 for $6 \mathrm{~h}$, after which the supernatant was aspirated and washed thrice with sterile PBS, followed by staining with SYTO $9(10 \mu \mathrm{M})$ and PI $(10 \mu \mathrm{M})$ according to the manufacturer's instructions. Stained biofilms on the culture plate were observed using a CLSM (Nikon A1+, Japan). The earliest and latest disappearance of fluorescence from the bottom of the biofilm to the surface was recorded layer by layer along the Z-axis, and the corresponding biofilm thickness was calculated accordingly; each layer was $1 \mu \mathrm{m}$. The resulting images stacks were quantified using ImageJ (USA) and then rendered in three-dimensional mode using image analysis software (NISElements AR 5.21.00, Japan).

\section{Statistical Analysis}

All data were analyzed using GraphPad Prism 8.0 (GraphPad Software, San Diego, CA, USA). Differences were analyzed by one-way ANOVA using Dunnett's analysis. Data are expressed as mean \pm standard deviation (Mean \pm $\mathrm{SD})$, and $P<0.05$ was considered statistically significant.

\section{Results}

\section{Antifungal Activity of AMP-I7 Against C. neoformans in vitro}

MIC values were evaluated the antifungal activity of AMP-17 against planktonic cells of $C$. neoformans. The results showed that AMP-17 had high antifungal activity against 18 strains of $C$. neoformans, with MIC values ranging from 4 to $16 \mu \mathrm{g} / \mathrm{mL}$ (Table 1). Similarly, FLC and AMB also displayed significant antifungal activity against C. neoformans planktonic cells, with MIC values of 2 to $8 \mu \mathrm{g} / \mathrm{mL}$ and 0.25 to $0.5 \mu \mathrm{g} / \mathrm{mL}$, respectively (Table 1). Notably, AMP-17, FLC, and AMB exhibited the most significant in vitro antifungal effects against C. neoformans IFM56769, with MIC values of 4,2 , and $0.25 \mu \mathrm{g} / \mathrm{mL}$, respectively.

\section{Growth Inhibition and Killing Kinetics}

Growth inhibition kinetics of AMP-17 were evaluated against $C$. neoformans at different time intervals. $1 \sim 8 \times$ MIC AMP17 showed a significant inhibitory effect on the growth curve of the tested fungi (Figure 1A). With increasing time, the inhibitory effect of low concentrations of AMP-17 on the fungal growth curve weakened; however, it still exhibited a significant inhibitory effect when compared to the control. Notably, the effectiveness of 2 and $8 \times$ MIC AMP-17 in inhibiting C. neoformans growth was comparable to that of $2 \times$ and $4 \times$ MIC FLC and AMB, respectively. The above data 
Table I MIC, $\mathrm{BIC}_{80}$ and $\mathrm{BEC}_{80}$ of AMP-I7 Against Cryptococcus neoformans

\begin{tabular}{|c|c|c|c|c|c|c|c|c|c|}
\hline \multirow[t]{2}{*}{ Strains } & \multicolumn{3}{|c|}{ MIC $(\mu \mathrm{g} / \mathrm{mL})$} & \multicolumn{3}{|c|}{$B I C_{80}(\mu g / m L)$} & \multicolumn{3}{|c|}{$\mathrm{BEC}_{80}(\mu \mathrm{g} / \mathrm{mL})$} \\
\hline & AMP-I7 & FLC & AMB & AMP-I7 & FLC & AMB & AMP-I 7 & FLC & AMB \\
\hline H99 & 16 & 8 & 0.5 & 32 & 128 & 4 & 128 & $>512$ & 32 \\
\hline KN99 & 8 & 4 & 0.5 & 16 & 256 & 4 & 128 & $>512$ & 32 \\
\hline IFM567I6 & 4 & 4 & 0.5 & 16 & 128 & 4 & 128 & $>512$ & 32 \\
\hline IFM56769 & 4 & 2 & 0.25 & 16 & 128 & 4 & 64 & $>512$ & 32 \\
\hline IFM5677I & 4 & 4 & 0.25 & 16 & 256 & 2 & 64 & $>512$ & 32 \\
\hline IFM56772 & 8 & 8 & 0.25 & 32 & 256 & 4 & 128 & $>512$ & 64 \\
\hline IFM56787 & 4 & 4 & 0.25 & 32 & 128 & 2 & 128 & $>512$ & 64 \\
\hline IFM56793 & 4 & 4 & 0.25 & 16 & 128 & 2 & 64 & $>512$ & 32 \\
\hline IFM56794 & 8 & 4 & 0.25 & 16 & 128 & 4 & 64 & $>512$ & 32 \\
\hline IFM56800 & 16 & 4 & 0.5 & 32 & 256 & 4 & 128 & $>512$ & 32 \\
\hline IFM56803 & 4 & 4 & 0.25 & 16 & 128 & 2 & 128 & $>512$ & 32 \\
\hline IFM56722 & 8 & 4 & 0.5 & 32 & 256 & 4 & 128 & $>512$ & 32 \\
\hline IFM56726 & 8 & 2 & 0.5 & 32 & 128 & 4 & 128 & $>512$ & 32 \\
\hline IFM56728 & 8 & 2 & 0.25 & 16 & 128 & 4 & 64 & $>512$ & 32 \\
\hline IFM5673I & 16 & 4 & 0.5 & 32 & 128 & 4 & 128 & $>512$ & 32 \\
\hline IFM56734 & 8 & 4 & 0.5 & 16 & 256 & 4 & 128 & $>512$ & 32 \\
\hline IFM56735 & 4 & 4 & 0.25 & 16 & 128 & 4 & 64 & $>512$ & 64 \\
\hline IFM56743 & 8 & 4 & 0.5 & 32 & 256 & 8 & 128 & $>512$ & 32 \\
\hline
\end{tabular}

Note: MIC, BIC and BEC were representative consensus value of at least two independent experiments, each performed in triplicate.

Abbreviations: AMP-I7, antimicrobial peptide-17; FLC, fluconazole; AMB, amphotericin B; MIC, minimal inhibitory concentration; BIC, biofilm inhibitory concentration; $B E C$, biofilm eradication concentration.

indicated that the growth of C. neoformans cells was inhibited by AMP-17 during all tested times. Furthermore, the timekilling kinetics of AMP-17 was performed on C. neoformans at concentrations of 1 8× MIC. As shown in Figure 1B, AMP-17 displayed concentration-dependent killing. The high concentration of AMP-17 (8× MIC) did not completely eliminate the colonies after $6 \mathrm{~h}$ of treatment, but still displayed in 2.9-log CFU reductions in C. neoformans. Subsequently, the number of CFU decreased with increasing time. However, the number of CFU increased slightly after FLC $(2 \times$ MIC) and AMP-17 $(2 \times$ MIC) treatments, but all CFU numbers decreased compared to the control $(P<$ 0.05). The killing kinetics of AMB (4× MIC) were demonstrated by eradicating the fungal cells in $3 \mathrm{~h}$.

\section{AMP-I7 Exerted Antifungal Effects by Disrupting Fungal Membrane}

The disruption of the cell membrane has been reported as a common or typical mode of action for some AMPs. Increasing experiments were carried out in this study to gain insight into the antifungal mechanism of AMP-17. To begin,
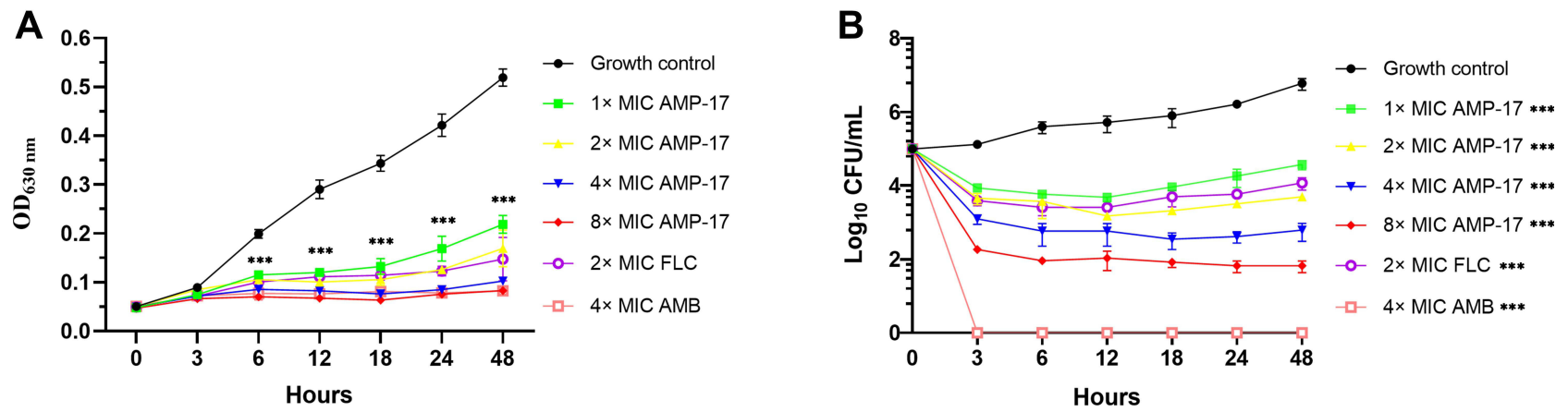

Figure I Inhibition and killing kinetics of AMP-I7 against C. neoformans IFM56769 planktonic cells. (A) Optical density measurements of exponentially growing C. neoformans at $630 \mathrm{~nm}$ in the presence and absence of AMP-I7 (I 8 MIC). (B) Time-killing kinetics of AMP-I7 against $C$. neoformans. $C$. neoformans cells (I0 $\left.0^{5} \mathrm{CFU} / \mathrm{mL}\right) \mathrm{were}$ cultured in wells containing AMP-I7 (I 8× MIC) to determine the killing of AMP-I7 against planktonic cells. Values are the mean \pm standard deviation of two experiments in triplicate and were analyzed by one-way ANOVA. Compared with the control, the asterisk represents statistically significant differences $(* * * P<0.00 \mathrm{I})$. 


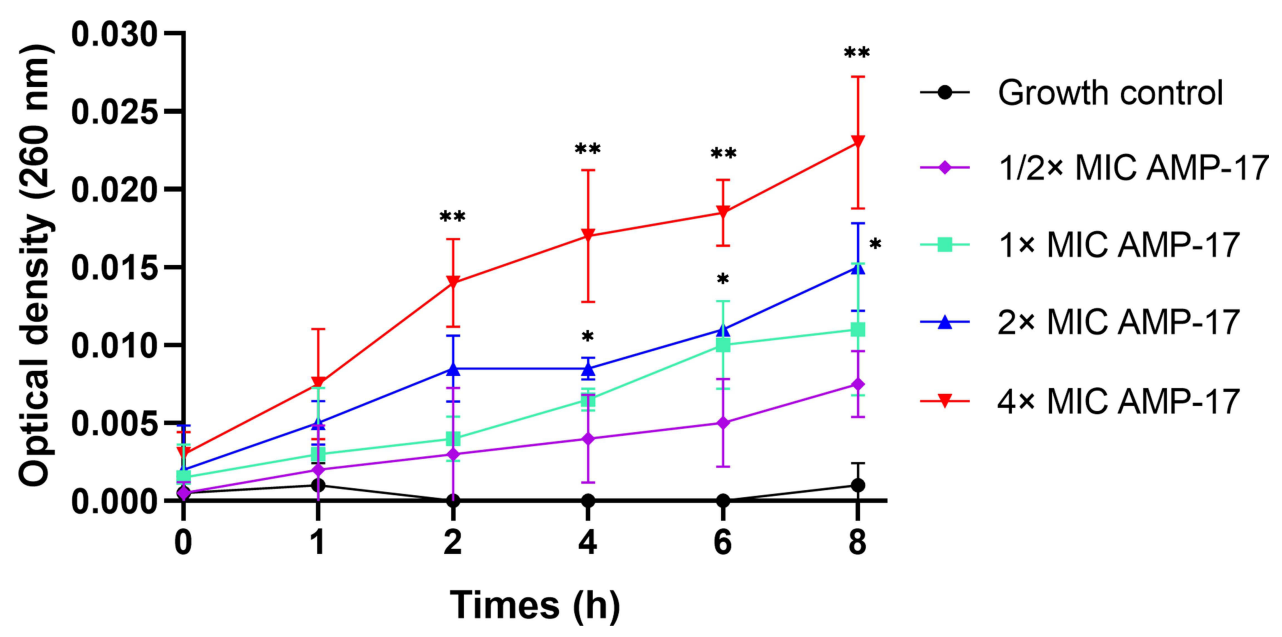

Figure 2 AMP- 17 treatment induces nucleotide release from C. neoformans IFM56769. Values are the mean \pm standard deviation of two experiments in triplicate and were analyzed by one-way ANOVA. Compared with the control, the asterisk represents statistically significant differences $(* P<0.05, * * P<0.0 \mathrm{I})$.

the most sensitive strain (IFM56769) for AMP-17, FLC, and AMB was chosen based on the above MIC data, and AMP17 damage to the membrane of $C$. neoformans was determined by measuring $260 \mathrm{~nm}$ of absorbing material. The $\mathrm{OD}_{260}$ nm of the AMP-17-treated cultures showed a dose and time-dependent increase (Figure 2) compared to the negative control. The above results suggest that AMP-17 may target the outer membrane of $C$. neoformans, causing intracellular material to leak out and increasing the maximum absorbance at $260 \mathrm{~nm}$.

To further confirm the damage of AMP-17 to $C$. neoformans membranes, C. neoformans cells treated with AMP-17 were observed by flow cytometry, CLSM, and SEM images. Flow cytometry analysis showed that the percentage of PIpositive cells was $0.76 \%$ in the absence of AMP-17. The cells were shown to be more damaged after treatment with AMP-17 at concentrations of $1 \times$ MIC, $2 \times$ MIC, and $4 \times$ MIC, with 7.24\%, 11.42\%, and 22.88\% PI fluorescence signals, respectively (Figures 3 and $\underline{\mathrm{S} 1}$ ). The above data suggested that AMP-17 may have played a significant role in degrading the membrane permeability of $C$. neoformans. Additionally, CLSM images revealed that after treatment with AMP-17 in C. neoformans for $6 \mathrm{~h}$, the red fluorescence (dead fungus) gradually increased with increasing AMP-17 concentration, implying that PI can penetrate the cell membrane and bind to DNA/RNA, resulting in characteristic red fluorescence, whereas the PBS control group showed no red fluorescence (Figure 4). Furthermore, SEM images showed that untreated C. neoformans cells were round or oval, with a smooth cell surface and distinct cell borders (Figure 5A). However, AMP-17 caused cells severe damage, including large differences in cell size, sunken surfaces, irregularities in shape, ruptured, shrunk, and leaked cytoplasmic contents (Figure 5B-D). These results suggested that AMP-17 may damage C. neoformans cells by disrupting the cell membrane.

\section{DNA-Binding Property Analysis}

It has been reported that the antifungal effect of AMPs is not restricted to membrane perforation; it can interact with intracellular targets (such as DNA). Thus, this study explored the possibility of intracellular targets by detecting the DNA binding properties of AMP-17. The results showed that AMP-17 was incapable of binding to genomic DNA, even though it was at a high concentration and treated with the DNA for $1 \mathrm{~h}$ (Figure S2 $)$, indicating that DNA is not one of the targets that causes the antifungal activity of AMP-17.

\section{Effect of AMP-I7 Against C. neoformans Biofilm Formation and Preformed Biofilm}

The potential and efficacy of AMP-17 against $C$. neoformans biofilm formation and pre-biofilm was determined in terms of $\mathrm{BIC}_{80}$ and $\mathrm{BEC}_{80}$ respectively. The results showed that $\mathrm{AMP}-17\left(\mathrm{BIC}_{80}: 16 \sim 32 \mu \mathrm{g} / \mathrm{mL} ; \mathrm{BEC}_{80}: 64 \sim 128 \mu \mathrm{g} / \mathrm{mL}\right), \mathrm{FLC}$ $\left(\mathrm{BIC}_{80}: 128 \sim 256 \mu \mathrm{g} / \mathrm{mL} ; \mathrm{BEC}_{80}:>512 \mu \mathrm{g} / \mathrm{mL}\right)$ and $\mathrm{AMB}\left(\mathrm{BIC}_{80}: 2 \sim 8 \mu \mathrm{g} / \mathrm{mL} ; \mathrm{BEC}_{80}: 32 \sim 64 \mu \mathrm{g} / \mathrm{mL}\right)$ could inhibit the biofilm formation and eradicated the pre-biofilm of $C$. neoformans (Table 1). Among them, the therapeutic effect of AMB 

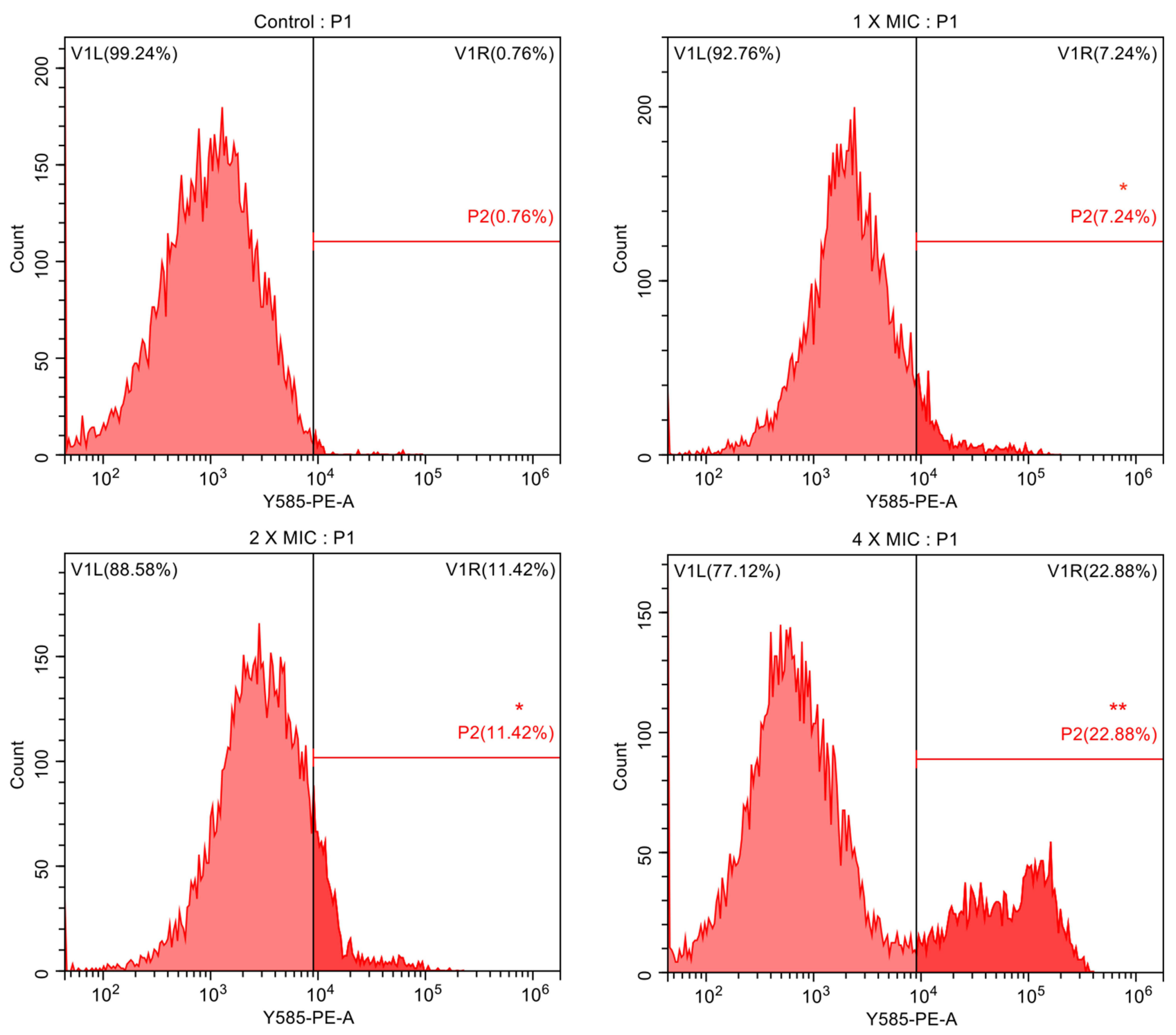

Figure 3 AMP-I7 induced membrane permeabilization of $C$. neoformans IFM56769. The fluorescence intensity of propidium iodide (PI) after 6 h of treatment with different concentrations of AMP-I7 (I, 2, and 4× MIC) was detected by flow cytometry. One representative results out of two independent experiments is shown. Compared with the control, the asterisk represents statistically significant differences $(* P<0.05, * * P<0.01)$.

is the most significant, followed by AMP-17, and finally FLC. Furthermore, biofilm-associated Cryptococcus cells were significantly more resistant to AMP-17, FLC and AMB than planktonic cells.

The biomass and metabolic activity of $C$. neoformans biofilms formation have gradually decreased with the increase of AMP-17 concentration. Compared with the negative control, biomass and metabolic activity were reduced by $78 \%$ and $86 \%$ at concentrations of AMP-17 of $64 \mu \mathrm{g} / \mathrm{mL}$, respectively (Figure $6 \mathrm{~A}$ and B). In addition, mature biofilms of C. neoformans also reduced significantly in biomass and metabolic activity after exposure to AMP-17. Biomass reductions of AMP-17 at $256 \mu \mathrm{g} / \mathrm{mL}$ reached $80 \%$, while reductions in metabolic activity reached $85 \%$, compared to the untreated control group (Figure 6C and D). Exposure of mature Cryptococcus biofilms to AMB resulted in a $90 \%$ reduction in metabolic activity at a concentration of $64 \mu \mathrm{g} / \mathrm{mL}$ (Figure 6E). However, Exposure to FLC only resulted in a $58 \%$ reduction in metabolic activity at a concentration of $512 \mu \mathrm{g} / \mathrm{mL}$ (Figure $6 \mathrm{~F}$ ). 


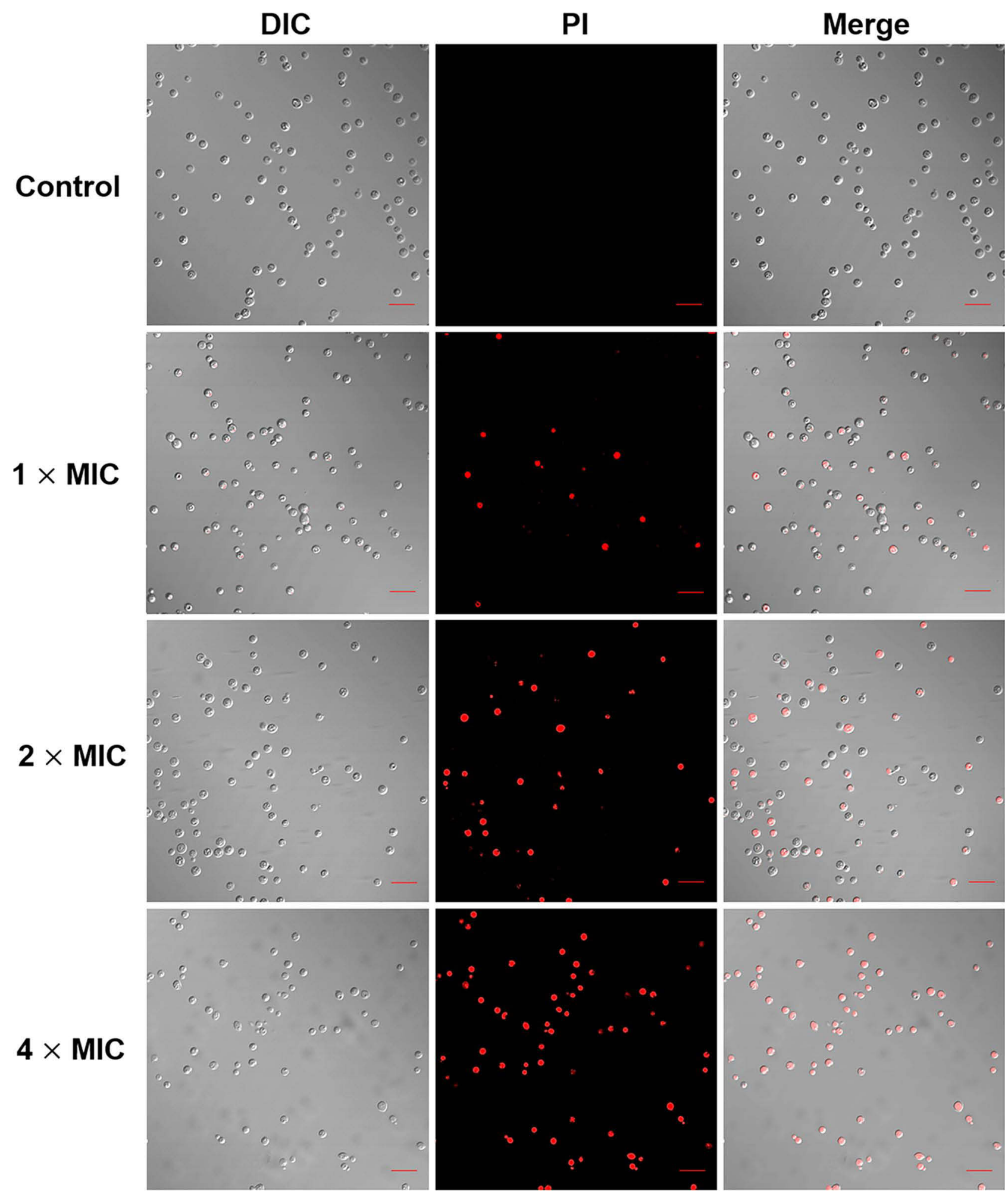

Figure 4 CLSM images of AMP-I7 treated C. neoformans planktonic cells. C. neoformans planktonic cells were incubated with control and AMP-I7 (I, 2 and $4 \times$ MIC) for 6 $\mathrm{h}$ at $35^{\circ} \mathrm{C}$. After staining with $10 \mu \mathrm{M}$ propidium iodide (PI), the red fluorescence in samples was detected by CLSM at $530 \mathrm{~nm}$ and $590 \mathrm{~nm}$ of excitation and emission. One representative results out of two independent experiments is shown. Images were captured using a $600 \times$ power field. Scale bar, $20 \mu \mathrm{m}$. 

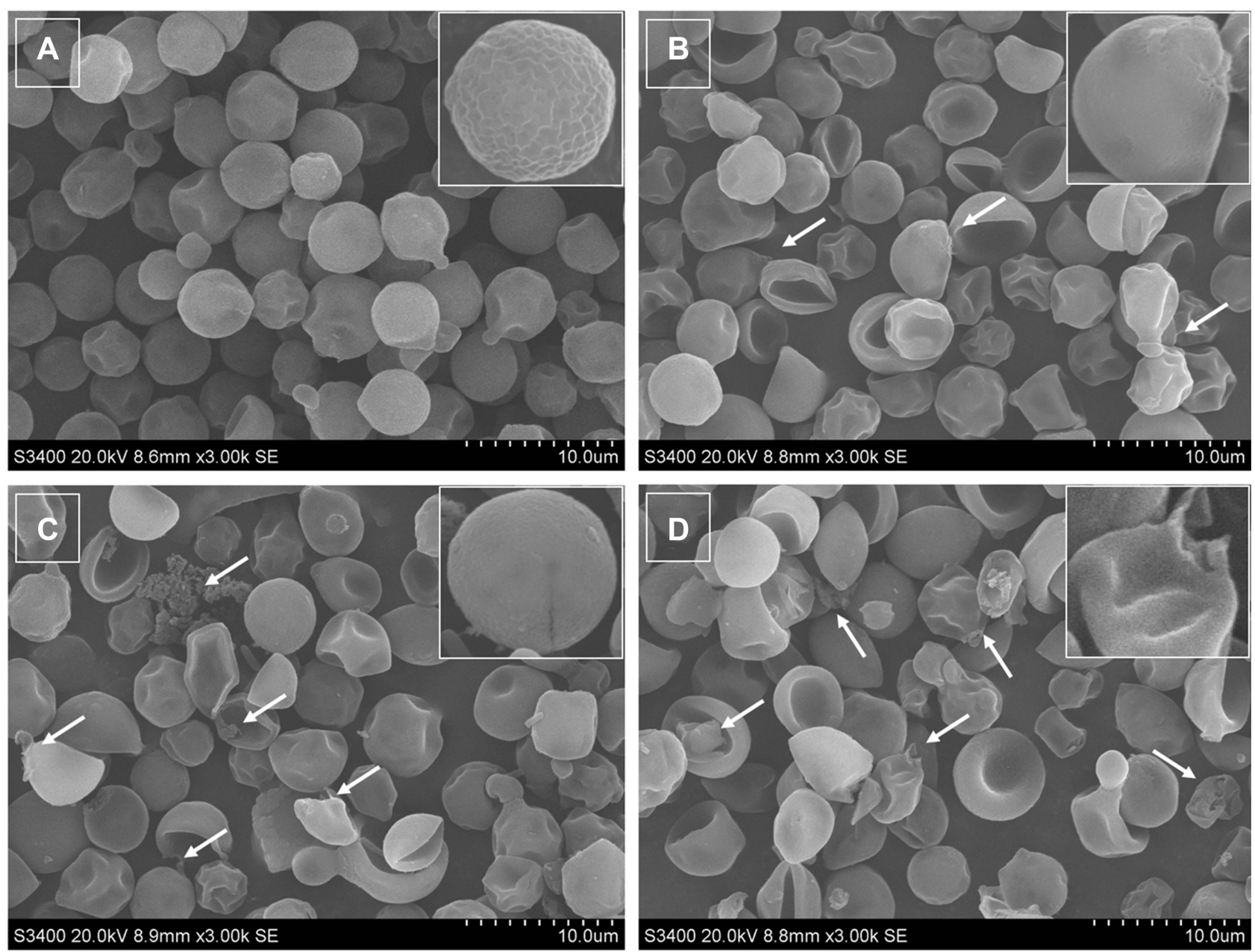

Figure 5 SEM images of AMP-I7-treated C. neoformans planktonic cells. Untreated $C$. neoformans cells presented a round or oval appearance, and the cell surface was smooth with clear cell boundaries (A). The cells treated with AMP-I7 (I, 2, and 4× MIC) at $6 \mathrm{~h}$ showed severe damage, such as the cell size differed greatly, the surface was sunken, irregularities in shape, and the cells ruptured and shrunk (B, C and D). One representative results out of two independent experiments is shown. Images were captured using a $3000 \times$ power field. Scale bar, $10 \mu \mathrm{m}$.

\section{Analyzing the Changes in Biofilm Cells Morphology After AMP-I7 Treatment}

To corroborate the anti-biofilm activity of AMP-17, OM and CLSM images were used to visualize the pre-biofilms after treatment with AMP-17. OM images showed the presence of many extracellular matrix (ECM), micro and macro-colonies in the untreated biofilm, and the yeast cells aggregated into clusters to form multilayered membrane-like structures (Figure $\underline{\mathrm{S} 3 \mathrm{~A}})$. After treatment with AMP-17 $\left(1 / 2,1\right.$, and $\left.2 \times \mathrm{BEC}_{80}\right)$ for $6 \mathrm{~h}$, the biofilm structure was destroyed and the cells were loosely distributed (Figure S3B-D). In addition, CLSM images found that a large number of biofilms aggregated in the negative control, mainly living fungi that emit green fluorescence (Figure 7A), with a biofilm thickness of $15 \mu \mathrm{m}$ (Figure 7E). The number of sessile cells was reduced and a dense biofilm could not be produced after treatment with AMP-17 (1/2, 1, and $2 \mathrm{BEC}_{80}$ ) for $6 \mathrm{~h}$ (Figure 7B-D), with biofilm thicknesses of $10 \mu \mathrm{m}, 9 \mu \mathrm{m}$, and $7 \mu \mathrm{m}$, respectively (Figure 7E). Meanwhile, the number of dead fungi gradually increased, and many fungi in the field of vision emitted red fluorescence. The statistical analysis of at least three biofilm images of each group displayed a high proportion of dead fungus (PI intensity) in the AMP17 treated biofilms (35.01\%, 41.02\%, and 49.29\%) as compared to the control group (20.83\%) (Figure 7F). The above results indicated that AMP-17 had the potential ability to eradicate the pre-biofilm of C. neoformans. 
A

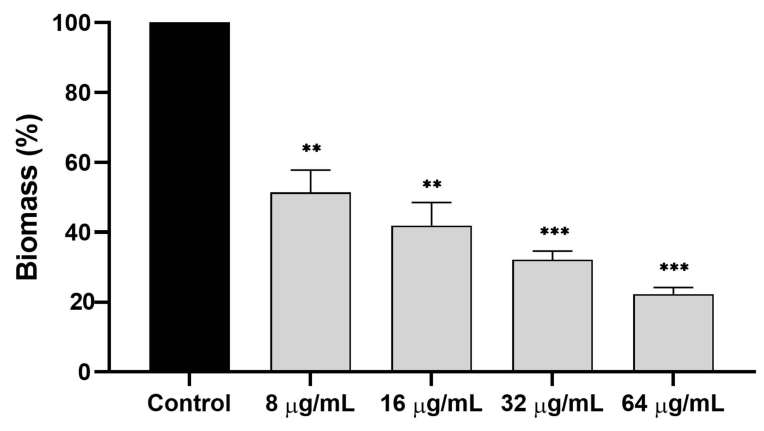

AMP-17

C

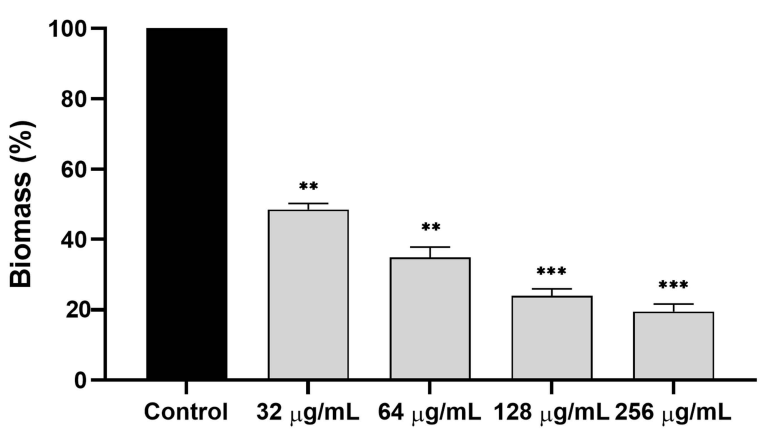

AMP-17

E

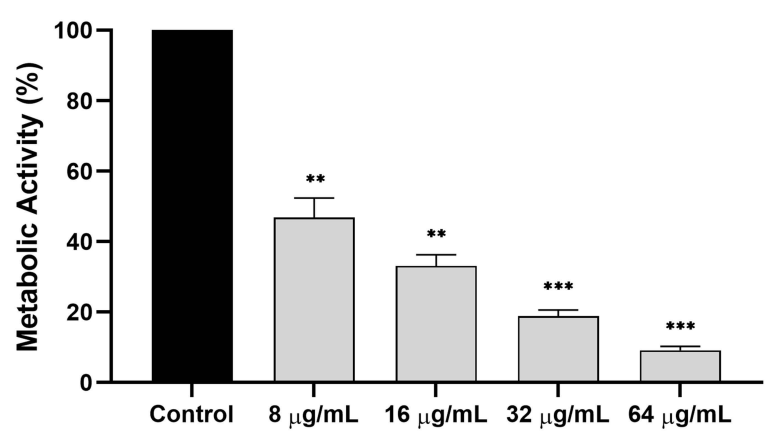

Amphotericin B

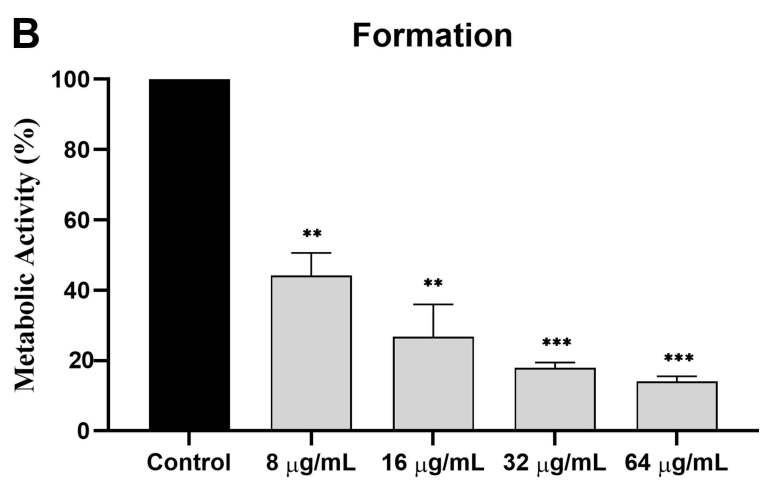

AMP-17
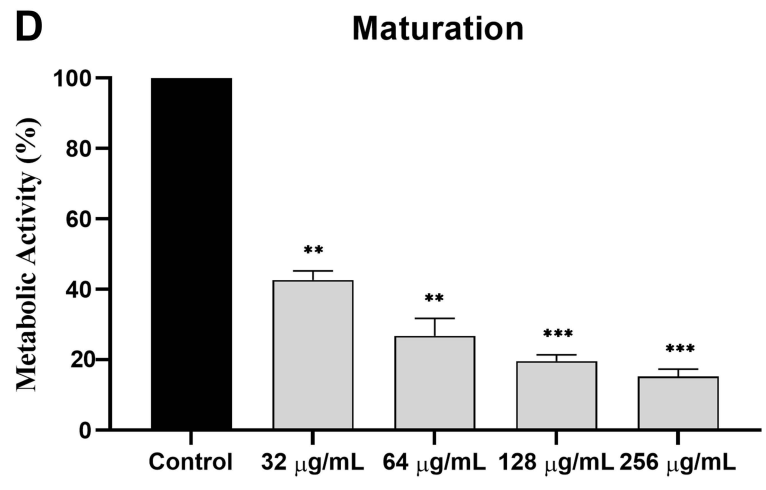

AMP-17

F

Maturation

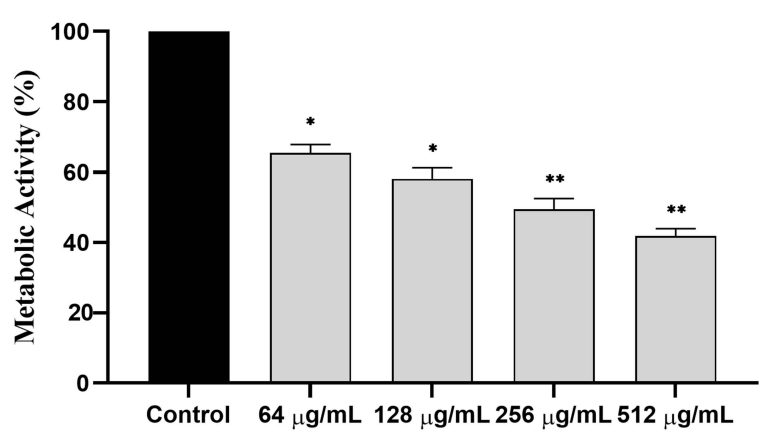

Fluconazole

Figure 6 Effect of AMP-17 on biofilm formation and pre-biofilm of Cryptococcus sp ( $\mathrm{n}=18$ ). Biomass (A and C) and metabolic activity (B, D, E and F). Black bars represent control. Gray bars represent cells exposed to different concentrations of AMP-17, FLC and AMB. Values are the mean \pm standard deviation of two experiments in triplicate and were analyzed by one-way ANOVA. Compared with the control, the asterisk represents statistically significant differences $(* P<0.05, * * P<0.0 \mathrm{I}, * * * P<0.00 \mathrm{I})$.

\section{Discussion}

Cryptococcus neoformans is one of the common human fungal pathogens in clinically impaired individuals, and cryptococcal meningitis caused by it remains a significant cause of morbidity and mortality amongst patients living with human immunodeficiency virus (HIV). ${ }^{39,40}$ In addition, the emergence of drug-resistant strains and their capacity to establish recalcitrant biofilms in medical settings is a major concern associated with managing cryptococcosis. ${ }^{41}$ Furthermore, $C$. neoformans biofilms are resistant to antifungal agents and host defense mechanisms, resulting in high morbidity and mortality. ${ }^{42}$ Therefore, it has become indispensable to identify or develop a novel class of agents that are 

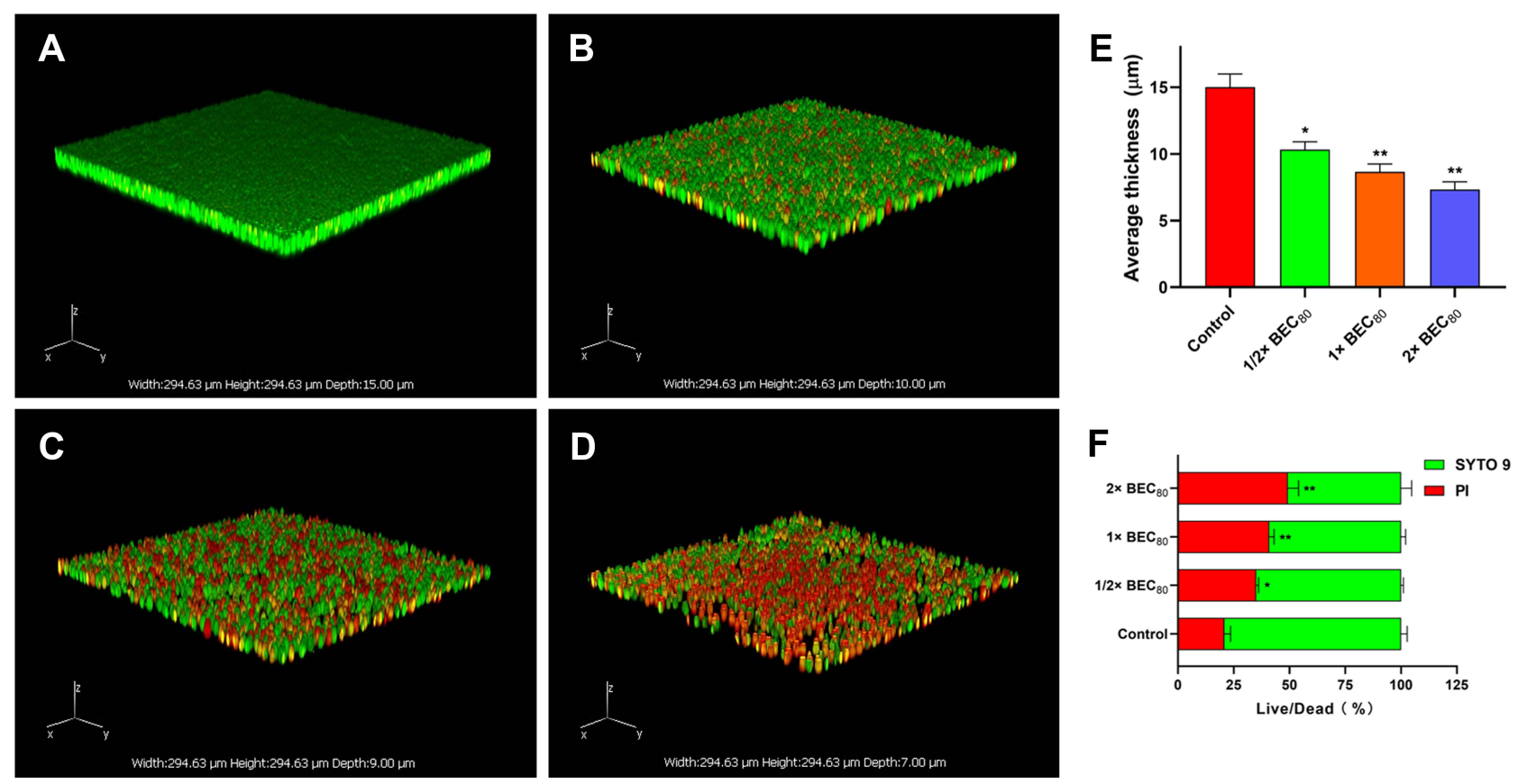

Figure 7 Quantitative analysis of pre-biofilm thickness and live/dead staining by CLSM. C. neoformans biofilms were formed on sterile polylysine-treated cover glass slides for $48 \mathrm{~h}$ at $35^{\circ} \mathrm{C}(\mathbf{A})$. Biofilms were treated with AMP-I7 (I/2, I, and $\left.2 \times \mathrm{BEC}_{80}\right)$ for $6 \mathrm{~h}$ at $35^{\circ} \mathrm{C}$ and subsequently stained with SYTO 9 and PI for I5 min in the dark (B, C, and (D). Images were captured using a $600 \times$ power field. The thickness (E) and live/dead ratio (F) of biofilm were calculated based on the fluorescence intensity. The results are taken from the average of three independent experiments. The data represents the mean \pm SD. $* P<0.05$ and $* * P<0.01$ compared to the non-drug control.

natural and directed against targets that do not impart selective pressure or promote drug resistance. Recently, some AMPs have demonstrated antifungal and anti-biofilm activity, also called anti-biofilm peptides. ${ }^{43-45}$ This study discovered that AMP-17 has effective antifungal activity against C. neoformans planktonic cells and biofilm, suggesting that AMP-17 shows potential as a novel antifungal agent.

In the present study, planktonic susceptibility tests against 18 fungal strains indicated that AMP-17, FLC, and AMB had significant in vitro antifungal activity against C. neoformans. Among them, AMP-17, FLC and AMB showed the most significant activity against $C$. neoformans IFM56769 with $\mathrm{MIC}_{80}$ of 4,2 and $0.25 \mu \mathrm{g} / \mathrm{mL}$, respectively. This phenomenon suggested that AMP-17 had different antifungal activities against strains of the same genus, which might be due to differences in the fungal cell wall. Glycoproteins and polysaccharides (dextran and chitin) make up the majority of fungal cell walls, but there are other components that vary by fungal species. ${ }^{46}$ Furthermore, the inhibitory and killing effects of AMP-17 were also observed in the current study. The results showed that AMP-17 exhibited inhibitory activity against the growth of $C$. neoformans planktonic cells, and there was a correlation between the concentration of AMP-17 and antifungal activity. The growth of $C$. neoformans cells was almost fully inhibited by 4 and $8 \times$ MIC AMP-17 during all the time of incubation. Meanwhile, the $2 \times$ and $4 \times$ MIC of AMP-17 inhibited C. neoformans growth with comparable efficiency to the $2 \times$ and $4 \times$ MIC of the clinical drugs FLC and AMB, respectively. In addition, the time-kill results showed that $4 \times$ and $8 \times$ MIC AMP-17 did not completely eliminate CFU after $6 \mathrm{~h}$ of treatment. However, it still influences a 2.1 and 2.9-log reduction in CFU of C. neoformans, respectively. In contrast, FLC ( $\times$ MIC) also failed to completely eliminate colonies, leading to only a 1.6-log reduction in C. neoformans CFU after $6 \mathrm{~h}$ of treatment, whereas AMB $(4 \times$ MIC) completely eradicated fungal cells within $3 \mathrm{~h}$. The mechanisms by which AMPs kill microorganisms vary case by case and are largely unknown. However, several proposed mechanisms for killing fungi share some common features. For example, most AMPs can disrupt the integrity of the fungal cell membrane and wall, and to achieve this, interaction between AMP molecules and fungal membrane and wall components is necessary. ${ }^{47,48}$ Through monitoring nucleotide leakage in C. neoformans, we found that AMP-17 led to an increase in nucleotide release, suggesting an increase in fungal cell permeability likely caused by disturbance of the fungal cell wall and membrane. Most $\alpha$-helical antifungal peptides have been reported to exert antifungal activity by interfering with membrane 
permeability. ${ }^{31} \mathrm{PI}$, a membrane-impermeable dye, was used to detect cells that had permeable membranes. PI enters into cells and binds to nucleic acids, fluorescing red. Flow cytometry analysis found that AMP-17 treatment significantly increased membrane permeability. Furthermore, CLSM images revealed a significant increase in the number of PI stained cells in C. neoformans cells treated with AMP-17, suggesting that AMP-17 may exert its antifungal effect by destroying the integrity of fungal cell membranes. Moreover, SEM images testified severe damage to $C$. neoformans cells treated with AMP-17, such as cell deformation, depression, shrinkage, and rupture, indicating that AMP-17 may be the result of direct interaction with cell wall and cell membrane components. However, membrane penetration was not the only way that AMPs killed microorganisms. Some reports indicate that AMPs can exert anti-fungal activity through multiple pathways (such as DNA, RNA, and protein). ${ }^{48,49}$ Thus, the ability of AMP-17 to bind fungal DNA was evaluated in this study. The data indicated that DNA was not one of the targets that causes the antifungal activity of AMP-17.

It has been reported that cryptococcal biofilms are less sensitive to antifungal agents and to various antimicrobial molecules produced by the immune system, ${ }^{20}$ and it is able to form biofilms on glass surfaces and in individual wells of polystyrene plates. $^{20,50,51}$ The formation of $C$. neoformans biofilm mainly follows the following events: surface attachment of fungi, formation of micro-colonies, and matrix production. ${ }^{17,52}$ However, the development of biofilm depends on the release of capsular polysaccharides to solid surfaces to produce an extracellular polysaccharide matrix (EPM). ${ }^{17}$ Glucuronoxylomannan (GXM) is the main component of polysaccharide capsules, which play a central role in the formation of biofilm and its pathogenesis. ${ }^{17,53}$ The release of $C$. neoformans GXM is necessary for adhesion to solid supports and the subsequent formation of biofilms had been confirmed. ${ }^{17}$ However, it is difficult to eradicate the infection with antifungal agents if the biofilm is established. Biofilms constitute a physical barrier that prevents the effective penetration of antifungal agents. Compared with planktonic cells, biofilms confer higher antifungal activity to microorganisms that form biofilms. ${ }^{54,55}$ In the current study, we investigated that AMP-17 exhibited effective anti-biofilm activity against $C$. neoformans. AMP-17 effectively reduced the biomass and metabolic activity of the biofilm formation and prebiofilm stages at concentrations of $8 \sim 64 \mu \mathrm{g} / \mathrm{mL}$ and $32 \sim 256 \mu \mathrm{g} / \mathrm{mL}$, respectively. Furthermore, AMB significantly reduced the metabolic activity of pre-biofilm at concentrations ranging from 8 to $64 \mathrm{~g} / \mathrm{mL}$. However, compared to AMP-17, increasing concentrations of the positive control (fluconazole) resulted in a significant increase in biofilm biomass and metabolic activity. This phenomenon confirms that Cryptococcus biofilms are less sensitive to antifungal agents and various antimicrobial molecules produced by the immune system, as reported by Martinez et al ${ }^{20}$ and Brilhante et al. ${ }^{34}$

From the analysis of OM images, it was shown that due to the increase in the amount of extracellular material surrounding the cells, the microstructure of $C$. neoformans biofilm became more complex and formed a dense structure closely attached to the plastic support. After AMP- 17 was treated for 6h, C. neoformans failed to form a dense biofilm, and the biofilm was easily detached, and the cells were decreased, damaged or collapsed. The CLSM results further quantified the thickness of the biofilm and the ratio of live/dead fungi, and the results found that after $48 \mathrm{~h}$, the biofilm formed on the coverslip was thick and dense, mainly composed of live fungi with a thickness of approximately $15 \mu \mathrm{m}$. After treatment with AMP-17, the number of dead fungi gradually increased, and the biofilm became significantly thinner. Thus, the above findings indicated that AMP-17 had potential eradication ability against the pre-biofilm of C. neoformans.

\section{Conclusion}

In summary, this study showed that AMP-17 had antifungal activity against planktonic cells and biofilm of C. neoformans. Furthermore, AMP-17 acted not only on the cell membrane but also on the intracellular level, indicating that the antimicrobial peptide may have a multi-target mechanism that results in fungus death. Therefore, these results indicated a promising treatment strategy for Cryptococcus-related infections, as well as a theoretical foundation for the investigation of novel AMP mechanisms. However, this study was restricted to in vitro experiments. Further research should be more validated in vivo, which might be one strategy to treat associated cryptococcosis.

\section{Acknowledgments}

This work was supported by the National Natural Science Foundation of China [grant numbers: 81760647, 82060381] and Key Technologies R\&D Program for Science and Technology Department of Guizhou Province ([2019]2823). 


\section{Author Contributions}

All authors contributed toward data analysis, drafting and critically revising the paper, gave final approval of the version to be published, and agree to be accountable for all aspects of the work.

\section{Disclosure}

Prof. Dr. Guo Guo reports a licensed patent ZL 2016 10428119. 8. The authors report no conflicts of interest in this work.

\section{References}

1. Zavala S, Baddley JW. Cryptococcosis. Semin Respir Crit Care Med. 2020;41(1):69-79. doi:10.1055/s-0039-3400280

2. Coelho C, Bocca AL, Casadevall A. The intracellular life of Cryptococcus neoformans. Annu Rev Pathol. 2014;9(1):219-238. doi:10.1146/ annurev-pathol-012513-104653

3. Kronstad JW, Attarian R, Cadieux B, et al. Expanding fungal pathogenesis: Cryptococcus breaks out of the opportunistic box. Nat Rev Microbiol. 2011;9(3):193-203. doi:10.1038/nrmicro2522

4. Shorman M, Evans D, Gibson C, et al. Cases of disseminated cryptococcosis in intravenous drug abusers without HIV infection: a new risk factor? Med Mycol Case Rep. 2016;14:17-19. doi:10.1016/j.mmcr.2016.12.003

5. Williamson PR, Jarvis JN, Panackal AA, et al. Cryptococcal meningitis epidemiology, immunology, diagnosis and therapy. Nat Rev Neurol. 2017;13(1):13-24. doi:10.1038/nrneurol.2016.167

6. Santos-Gandelman J, Machado-Silva A. Drug development for cryptococcosis treatment: what can patents tell us? Mem Inst Oswaldo Cruz. 2019;114:e180391. doi:10.1590/0074-02760180391

7. Rajasingham R, Smith RM, Park BJ, et al. Global burden of disease of HIV-associated cryptococcal meningitis: an updated analysis. Lancet Infect Dis. 2017;17(8):873-881. doi:10.1016/S1473-3099(17)30243-8

8. Perfect JR, Dismukes WE, Dromer F, et al. Clinical practice guidelines for the management of cryptococcal disease: 2010 update by the Infectious Diseases Society of America. Clin Infect Dis. 2010;50(3):291-322. doi:10.1086/649858

9. Garvey EP, Sharp AD, Warn PA, et al. The novel fungal CYP51 inhibitor VT-1598 is efficacious alone and in combination with liposomal amphotericin B in a murine model of cryptococcal meningitis. J Antimicrob Chemoth. 2018;73(10):2815-2822. doi:10.1093/jac/dky242

10. Loyse A, Thangaraj H, Easterbrook P, et al. Cryptococcal meningitis: improving access to essential antifungal medicines in resource-poor countries. Lancet Infect Dis. 2013;13(7):629-637. doi:10.1016/S1473-3099(13)70078-1

11. Kong Q, Cao Z, Lv N, et al. Minocycline and fluconazole have a synergistic effect against Cryptococcus neoformans both in vitro and in vivo. Front Microbiol. 2020;11:836. doi:10.3389/fmicb.2020.00836

12. May RC, Stone NR, Wiesner DL, et al. Cryptococcus: from environmental saprophyte to global pathogen. Nat Rev Microbiol. 2016;14(2):106-117. doi:10.1038/nrmicro.2015.6

13. Datta A, Yadav V, Ghosh A, et al. Mode of action of a designed antimicrobial peptide: high potency against Cryptococcus neoformans. Biophys J. 2016;111(8):1724-1737. doi:10.1016/j.bpj.2016.08.032

14. Mayer FL, Kronstad JW. Disarming fungal pathogens: Bacillus safensis inhibits virulence factor production and biofilm formation by Cryptococcus neoformans and Candida albicans. mBio. 2017;8(5):e01537-17. doi:10.1128/mBio.01537-17

15. Ramage G, Williams C. Chapter two-the clinical importance of fungal biofilms. Adv Appl Microbiol. 2013;84(4):27-83. doi:10.1016/B978-0-12407673-0.00002-3

16. Kumari P, Mishra R, Arora N, et al. Antifungal and anti-biofilm activity of essential oil active components against Cryptococcus neoformans and Cryptococcus laurentii. Front Microbiol. 2017;8:2161. doi:10.3389/fmicb.2017.02161

17. Martinez LR, Casadevall A. Specific antibody can prevent fungal biofilm formation and this effect correlates with protective efficacy. Infect Immun. 2005;73(10):6350-6362. doi:10.1128/IAI.73.10.6350-6362.2005

18. Casadevall A, Steenbergen JN, Nosanchuk JD. 'Ready made' virulence and 'dual use' virulence factors in pathogenic environmental fungi-the Cryptococcus neoformans paradigm. Curr Opin Microbiol. 2003;6(4):332-337. doi:10.1016/s1369-5274(03)00082-1

19. Hall-Stoodley L, Costerton JW, Stoodley P. Bacterial biofilms: from the natural environment to infectious diseases. Nat Rev Microbiol. 2004;2 (2):95-108. doi:10.1038/nrmicro821

20. Martinez LR, Casadevall A. Cryptococcus neoformans cells in biofilms are less susceptible than planktonic cells to antimicrobial molecules produced by the innate immune system. Infect Immun. 2006;74(11):6118-6123. doi:10.1128/IAI.00995-06

21. Jhong JH, Chi YH, Li WC, et al. dbAMP: an integrated resource for exploring antimicrobial peptides with functional activities and physicochemical properties on transcriptome and proteome data. Nucleic Acids Res. 2019;47(D1):D285-D297. doi:10.1093/nar/gky1030

22. Fjell CD, Hiss JA, Hancock RE, et al. Designing antimicrobial peptides: form follows function [published correction appears in Nat Rev Drug Discov. 2012 Feb;11(2):168]. Nat Rev Drug Discov. 2011;11(1):37-51. doi:10.1038/nrd3591

23. van der Does AM, Hiemstra PS, Mookherjee N. Antimicrobial host defence peptides: immunomodulatory functions and translational prospects. Adv Exp Med Biol. 2019;1117:149-171. doi:10.1007/978-981-13-3588-4_10

24. Xiu JF, Wang T, Wang Y, et al. Histological observation and expression patterns of antimicrobial peptides during fungal infection in Musca domestica (Diptera: muscidae) larvae. Braz Arch Biol Technol. 2016;59:1-13. doi:10.1590/1678-4324-2016160147

25. Guo G, Tao R, Li Y, et al. Identification and characterization of a novel antimicrobial protein from the housefly Musca domestica. Biochem Biophys Res Commun. 2017;490(3):746-752. doi:10.1016/j.bbrc.2017.06.112

26. Yang LB, Guo G, Zhao XY, et al. Antifungal activity and physicochemical properties of a novel antimicrobial protein AMP-17 from Musca domestica. Pol J Microbiol. 2019;68(3):383-390. doi:10.33073/pjm-2019-041

27. Ma H, Zhao X, Yang L, et al. Antimicrobial peptide AMP-17 affects Candida albicans by disrupting its cell wall and cell membrane integrity. Infect Drug Resist. 2020;13:2509-2520. doi:10.2147/IDR.S250278 
28. CLSI. Reference Method for Broth Dilution Antifungal Susceptibility Testing of Yeasts: Approved Standard-Third Edition. M27-A3 Ed. (CLSI, Ed.). Wayne, PA: Clinical and Laboratory Standards Institute; 2008.

29. Seyedjavadi SS, Khani S, Eslamifar A, et al. The antifungal peptide MCh-AMP1 derived from Matricaria chamomilla inhibits Candida albicans growth via inducing ROS generation and altering fungal cell membrane permeability. Front Microbiol. 2020;10:3150. doi:10.3389/ fmicb.2019.03150

30. Lemos ASO, Florêncio JR, Pinto NCC, et al. Antifungal activity of the natural coumarin scopoletin against planktonic cells and biofilms from a multidrug-resistant Candida tropicalis strain. Front Microbiol. 2020;11:1525. doi:10.3389/fmicb.2020.01525

31. Yang Y, Wang C, Gao N, et al. A novel dual-targeted $\alpha$-Helical peptide with potent antifungal activity against fluconazole-resistant Candida albicans clinical isolates. Front Microbiol. 2020;11:548620. doi:10.3389/fmicb.2020.548620

32. Li L, Sun J, Xia S, et al. Mechanism of antifungal activity of antimicrobial peptide APP, a cell-penetrating peptide derivative, against Candida albicans: intracellular DNA binding and cell cycle arrest. Appl Microbiol Biotechnol. 2016;100(7):3245-3253. doi:10.1007/s00253-015-7265-y

33. Pierce CG, Uppuluri P, Tristan AR, et al. A simple and reproducible 96-well plate-based method for the formation of fungal biofilms and its application to antifungal susceptibility testing. Nat Protoc. 2008;3(9):1494-1500. doi:10.1038/nport.2008.141

34. Brilhante RSN, Gotay WJP, Pereira VS, et al. Antifungal activity of promethazine and chlorpromazine against planktonic cells and biofilms of Cryptococcus neoformans/Cryptococcus gattii complex species. Med Mycol. 2020;58(7):906-912. doi:10.1093/mmy/myz140

35. Martinez LR, Casadevall A. Cryptococcus neoformans biofilm formation depends on surface support and carbon source and reduces fungal cell susceptibility to heat, cold, and UV light. Appl Environ Microbiol. 2007;73(14):4592-4601. doi:10.1128/AEM.02506-06

36. Quinteros MA, Galera ILD, Tolosa J, et al. Novel antifungal activity of oligostyrylbenzenes compounds on Candida tropicalis biofilms. Med Mycol. 2021;59(3):244-252. doi:10.1093/mmy/myaa046

37. Ravi S, Pierce C, Witt C, et al. Biofilm formation by Cryptococcus neoformans under distinct environmental conditions. Mycopathologia. 2009;167 (6):307-314. doi:10.1007/s11046-008-9180-6

38. Liu W, Wu Z, Mao C, et al. Antimicrobial peptide Cec4 eradicates the bacteria of clinical carbapenem-resistant Acinetobacter baumannii biofilm. Front Microbiol. 2020;11:1532. doi:10.3389/fmicb.2020.01532

39. Spec A, Powderly WG. Cryptococcal meningitis in AIDS. Handb Clin Neurol. 2018;152:139-150. doi:10.1016/B978-0-444-63849-6.00011-6

40. Lawrence DS, Boyer-Chammard T, Jarvis JN. Emerging concepts in HIV-associated cryptococcal meningitis. Curr Opin Infect Dis. 2019;32 (1):16-23. doi:10.1097/QCO.0000000000000514

41. Smith KD, Achan B, Hullsiek KH, et al. Increased antifungal drug resistance in clinical isolates of Cryptococcus neoformans in Uganda. Antimicrob Agents Chemother. 2015;59(12):7197-7204. doi:10.1128/AAC.01299-15

42. Martinez LR, Casadevall A. Biofilm formation by Cryptococcus neoformans. Microbiol Spectr. 2015;3(3). doi:10.1128/microbiolspec.MB-00062014

43. Raman N, Lee MR, Rodríguez López AL, et al. Antifungal activity of a $\beta$-peptide in synthetic urine media: toward materials-based approaches to reducing catheter-associated urinary tract fungal infections. Acta Biomater. 2016;43:240-250. doi:10.1016/j.actbio.2016.07.016

44. Ma L, Ye X, Sun P, et al. Antimicrobial and antibiofilm activity of the EeCentrocin 1 derived peptide EC1-17KV via membrane disruption. EBioMedicine. 2020;55:102775. doi:10.1016/j.ebiom.2020.102775

45. Yang Y, Chen F, Chen HY, et al. A Novel antimicrobial peptide scyreprocin from mud crab Scylla paramamosain showing potent antifungal and anti-biofilm activity. Front Microbiol. 2020;11:1589. doi:10.3389/fmicb.2020.01589

46. Tan L, Bai L, Wang L, et al. Antifungal activity of spider venom-derived peptide lycosin-I against Candida tropicalis. Microbiol Res. 2018;216:120-128. doi:10.1016/j.micres.2018.08.012

47. Cortés JCG, Curto MÁ, Carvalho VSD, et al. The fungal cell wall as a target for the development of new antifungal therapies. Biotechnol Adv. 2019;37(6):107352. doi:10.1016/j.biotechadv.2019.02.008

48. van der Weerden NL, Bleackley MR, Anderson MA. Properties and mechanisms of action of naturally occurring antifungal peptides. Cell Mol Life Sci. 2013;70(19):3545-3570. doi:10.1007/s00018-013-1260-1

49. Le CF, Fang CM, Sekaran SD. Intracellular targeting mechanisms by antimicrobial peptides. Antimicrob Agents Chemother. 2017;61(4):e02340-16. doi:10.1128/AAC.02340-16

50. Tavares ER, Gionco B, Morguette AEB, et al. Phenotypic characteristics and transcriptome profile of Cryptococcus gattii biofilm. Sci Rep. 2019;9 (1):6438. doi:10.1038/s41598-019-42896-2

51. Korem M, Kagan S, Polacheck I. The effect of novel heterocyclic compounds on cryptococcal biofilm. J Fungi. 2017;3(3):42. doi:10.3390/ jof3030042

52. Martinez LR, Casadevall A. Susceptibility of Cryptococcus neoformans biofilms to antifungal agents in vitro. Antimicrob Agents Chemother. 2006;50(3):1021-1033. doi:10.1128/AAC.50.3.1021-1033.2006

53. Vecchiarelli A. Immunoregulation by capsular components of Cryptococcus neoformans. Med Mycol. 2000;38(6):407-417. doi:10.1080/ mmy.38.6.407.417

54. Al-Fattani MA, Douglas LJ. Penetration of candida biofilms by antifungal agents. Antimicrob Agents Chemother. 2004;48(9):3291-3297. doi:10.1128/AAC.48.9.3291-3297.2004

55. Chandra J, Kuhn DM, Mukherjee PK, et al. Biofilm formation by the fungal pathogen Candida albicans: development, architecture, and drug resistance. J Bacteriol. 2001;183(18):5385-5394. doi:10.1128/JB.183.18.5385-5394.2001 


\section{Publish your work in this journal}

Infection and Drug Resistance is an international, peer-reviewed open-access journal that focuses on the optimal treatment of infection (bacterial, fungal and viral) and the development and institution of preventive strategies to minimize the development and spread of resistance. The journal is specifically concerned with the epidemiology of antibiotic resistance and the mechanisms of resistance development and diffusion in both hospitals and the community. The manuscript management system is completely online and includes a very quick and fair peer-review system, which is all easy to use. Visit http://www.dovepress.com/testimonials.php to read real quotes from published authors.

Submit your manuscript here: https://www.dovepress.com/infection-and-drug-resistance-journal 